\title{
Influence of Korean pine (Pinus koraiensis)-seed oil containing cis-5,cis-9,cis-12-octadecatrienoic acid on polyunsaturated fatty acid metabolism, eicosanoid production and blood pressure of rats
}

\author{
BY MICHIHIRO SUGANO', IKUO IKEDA², KOSABURO WAKAMATSU ${ }^{2}$, \\ AND TAKAYUKI OKA ${ }^{2}$ \\ ${ }^{1}$ Laboratory of Food Science and ${ }^{2}$ Laboratory of Nutrition Chemistry, Kyushu University School of \\ Agriculture, Fukuoka 812, Japan
}

(Received 22 June 1993 - Revised 12 November 1993 - Accepted 15 February 1994)

\begin{abstract}
The effects of dietary Korean pine (Pinus koraiensis)-seed oil containing a peculiar trienoic acid (cis-5, cis-9,cis-12-18:3, pinolenic acid, approximately $18 \%$ ) on various lipid variables were compared in rats with those of flaxseed (Linum usitatissimum L.) oil, safflower (Carthamus tinctorius L.) oil and evening primrose (Oenothera biennis L.) oil under experimental conditions where the effects of different polyunsaturated fatty acids could be estimated. In Sprague-Dawley rats fed on diets containing $100 \mathrm{~g}$ fat and $5 \mathrm{~g}$ cholesterol/kg, the hypocholesterolaemic activity of pinolenic acid was intermediate between $a$-linolenic and linoleic acids. Analysis of the fatty acid composition of liver phosphatidylcholine indicated that, in contrast to $\alpha$-linolenic acid, pinolenic acid does not interfere with the desaturation of linoleic acid to arachidonic acid. However, the effects on ADP-induced platelet aggregation and aortic prostacyclin production were comparable. When spentaneously hypertensive rats were fed on diets containing $100 \mathrm{~g}$ fat $/ \mathrm{kg}$ but free of cholesterol, $\gamma$-linolenic and pinolenic acids, as compared with linoleic acid, increased prostacyclin production and tended to reduce platelet aggregation. In addition, pinolenic acid attenuated the elevation of blood pressure after 5 weeks of feeding. Thus, the results of the present studies indicate the beneficial effects of pinolenic acid on various lipid variables.
\end{abstract}

Pine-seed oil: Lipid metabolism: Platelet aggregation: Hypertension

Polyunsaturated fatty acids (PUFA), such as linoleic acid, exert several important metabolic functions after conversion to eicosanoids. However, excessive or imbalanced production of specific eicosanoids is closely related to the incidence of various degenerative diseases (Sugano \& Lee, 1989; Kinsella et al. 1990). For this reason, identification of PUFA which have hypocholesterolaemic activity but which are not readily converted to biologically active eicosanoids may be desirable. For example, columbinic acid (trans-5, cis9,cis-12-18:3) has essential fatty acid activity, but is hardly converted to prostaglandins due to the presence of the trans-double bond in its molecule (Houtsmuller, 1981). Peculiar eicosatrienoic and eicosatetraenoic acids in Biota (Biota orientalis)-seed oil have been shown to prevent a rise of plasma cholesterol due to feeding cholesterol, and simultaneously interfere with linoleic acid desaturation (Ikeda et al. 1992). The trienoic acid in Biota-seed oil is incorporated extensively into the phosphatidylinositol pool, suggesting a possible metabolic effect (Berger \& German, 1991).

In the present study we examined the effects of a new type of unfamiliar PUFA occurring in pine (Pinus koraiensis)-seed oil, pinolenic acid (cis-5,cis-9,cis-12-18:3), on various lipid variables including tissue lipid levels, PUFA metabolism, prostacyclin production, and 
Table 1. Fatty acid compositions of dietary fats

\begin{tabular}{|c|c|c|c|c|c|c|c|}
\hline \multirow[b]{2}{*}{ Dietary fat } & \multicolumn{7}{|c|}{ Fatty acid (g/100 g total fatty acids) } \\
\hline & $16: 0$ & $18: 0$ & $18: 1$ & $\begin{array}{c}18: 2 \\
n-6\end{array}$ & $\begin{array}{l}18: 3 \\
\mathrm{PO}^{*}\end{array}$ & $\begin{array}{c}18: 3 \\
n-6\end{array}$ & $\begin{array}{c}18: 3 \\
n-3\end{array}$ \\
\hline \multicolumn{8}{|l|}{ Expt 1} \\
\hline Safflower (Carthamus tinctorius L.) oil† & $5 \cdot 8$ & $2 \cdot 3$ & $30 \cdot 5$ & $60 \cdot 8$ & - & - & - \\
\hline Flaxseed (Linum usitatissimum L.) oil & $6 \cdot 1$ & $2 \cdot 5$ & $29 \cdot 8$ & $45 \cdot 9$ & - & - & $15 \cdot 5$ \\
\hline Pine-seed (Pinus koraiensis) oil & $5 \cdot 0$ & 20 & $26 \cdot 3$ & $45 \cdot 2$ & $17 \cdot 7$ & - & - \\
\hline \multicolumn{8}{|l|}{ Expt 2} \\
\hline Safflower oil & $7 \cdot 0$ & $2 \cdot 4$ & $12 \cdot 2$ & $78 \cdot 0$ & - & - & - \\
\hline Evening primrose (Oenothera biennis L.) oil & $6 \cdot 2$ & $1 \cdot 7$ & $8 \cdot 7$ & $72 \cdot 6$ & - & $10-6$ & - \\
\hline Pine-seed oil & $4 \cdot 8$ & $2 \cdot 1$ & $30 \cdot 3$ & $43 \cdot 4$ & $18 \cdot 2$ & - & - \\
\hline
\end{tabular}

platelet aggregation in rats. The effect on blood pressure was also examined in spontaneously hypertensive rats.

\section{MATERIALS AND METHODS}

\section{Animals and diets}

After acclimatization for 1 week, 5-week-old male Sprague-Dawley rats (Expt 1; Seiwa Experimental Animals, Yoshitomi, Japan) and 9-week-old male spontaneously hypertensive rats (SHR; Expt 2; Japan Charles River, Atsugi, Japan) were given an AIN-76type purified diet (American Institute of Nutrition, 1977) containing $(\mathrm{g} / \mathrm{kg})$ : casein 200, fat 100 , vitamin mixture 10 , mineral mixture 35 , choline bitartrate 2 , DL-methionine 3 , cellulose 50 , maize starch 150 , and sucrose to $1 \mathrm{~kg}$. Newly harvested pine seeds were obtained in Seoul, Korea, and the lipids were extracted with hexane and purified to an edible oil grade (purity, $>980 \mathrm{~g} / \mathrm{kg}$ as triacylglycerol). In Expt 1, safflower (Carthamus tinctorius L.) oil (SAO; Rinoru Oil Mills Co., Tokyo, Japan), flaxseed (Linum usitatissimum L.) oil (FSO; Nisshin Oil Mills Co., Tokyo, Japan) and pine-seed oil (PSO) were used as the dietary fat source, and the total content of PUFA in the former two oils was made equivalent to that of pine-seed oil by appropriately mixing with SAO and high-oleic-acid SAO (Table 1). Thus, the difference in the PUFA composition was the sole variable. The diet contained $5 \mathrm{~g}$ cholesterol $/ \mathrm{kg}$ and $1.25 \mathrm{~g}$ sodium cholate $/ \mathrm{kg}$ at the expense of sucrose. In Expt 2 the effect of pine-seed oil was compared with that of SAO and evening primrose (Oenothera biennis L.) oil (EPO; Riken Vitamins Co., Tokyo, Japan) in rats given diets free of cholesterol (Table 1). In this experiment, no adjustment was made since the content of PUFA in these oils was comparable. The rats were given diets and water ad lib. Food intake and body weight were measured every other day. Systolic blood pressure was measured every week using a sphygmomanometer (MK-100; Muromachi Kikai Co., Tokyo; Koba et al. 1992).

\section{Lipid analysis}

After feeding the experimental diets for $30 \mathrm{~d}$ (Expt 1) or 8 weeks (Expt 2) the rats were lightly anaesthetized with diethyl ether, and blood $(9 \mathrm{ml})$ was collected from the abdominal aorta into a syringe containing $1 \mathrm{ml}$ sodium citrate and indomethacin (final concentration $1 \times 10^{-4} \mathrm{M}$; Ikeda et al. 1992). The thoracic aorta was excised and incubated in phosphate 
buffer ( $\mathrm{pH} 7.40$ at $25^{\circ}$ for $30 \mathrm{~min}$ ). The concentration of prostacyclin in the medium was measured as 6-keto-prostaglandin $F_{1 \alpha}$ by radioimmunoassay (New England Nuclear, Boston, MA, USA; Lee et al. 1989). Platelets were separated, and the aggregation induced by $5 \mu \mathrm{M}$-ADP was measured using Aggrecorder II (Kyoto Daiichi Kagaku Co., Kyoto, Japan; Brox et al. 1981). Liver and plasma lipids were extracted with a mixture of chloroform-methanol (2:1, v/v; Folch et al. 1957), and the concentrations of cholesterol, triacylglycerol and phospholipid were measured as described previously (Sugano et al. 1976). Liver phosphatidylcholine and plasma cholesterol ester were separated by TLC, and their fatty acid compositions were measured by GLC (Ikeda et al. 1989).

\section{Statistical analysis}

Data were analysed by one-way analysis of variance followed by inspection of all differences by Duncan's new multiple-range test (Duncan, 1955).

\section{RESULTS}

Expt 1. Effects of pine-seed oil in Sprague-Dawley rats fed on cholesterol-enriched diets When cholesterol-enriched diets were given, PSO, as compared with FSO, did not influence food intake (18.9 (SE 0.7) and 19.2 (SE 1.0) g/d) or body-weight gain (207 (SE 8) and 221 (SE 15) g/30 d) of rats. The liver weight was comparable in these two groups of rats (both 63 (SE 2$) \mathrm{g} / \mathrm{kg}$ body weight). These variables were also comparable with those of rats fed on SAO (18.3 (SE 0.5) g/d, 201 (SE 6) $\mathrm{g}$ and 67 (SE 1) g/ kg body weight). Thus, pinolenic acid showed the same effect on growth performance as $\alpha$-linolenic and linoleic acids.

The hypocholesterolaemic effect was highest with FSO and lowest with SAO, PSO being intermediate (Table 2). The concentration of plasma phospholipid also showed a similar pattern of response, whereas that of plasma triacylglycerol tended to be lower in the FSO and PSO groups than in the SAO group. However, there was no significant dietary fatdependent difference in the concentration of high-density-lipoprotein (HDL)-cholesterol (1.30 (SE 0.11), 1.47 (SE 0.10) and 1.25 (SE 0.09) mmol/1 for the SAO, FSO and PSO groups respectively). In contrast, dietary fats did not influence the concentration of liver lipids (Table 2).

Since there were no detectable differences in the compositions of saturated and monounsaturated fatty acids in liver phosphatidylcholine, only those of PUFA are shown in Table 3. The proportion of arachidonic acid was significantly lower in the FSO group than in the PSO group although these fats contained a comparable amount of linoleic acid (see Table 1). The value for the PSO group was the same as that for the SAO group. In contrast, the proportion of linoleic acid was significantly higher in rats given FSO than in those given PSO, SAO being in between. Consequently, the desaturation index for linoleic acid, the ratio of $20: 3 n-6+20: 4 n-6$ to $18: 2 n-6$, was significantly higher in the PSO group than in the FSO group and even in the SAO group. The proportion of docosahexaenoic acid $(22: 6 n-3)$ was significantly higher in rats given FSO than in those given SAO or PSO as reflecting the dietary supply of $\alpha$-linolenic acid. A detectable amount of pinolenic acid was found in rats given PSO, while only a marginal amount of $\alpha$-linolenic acid was detected in rats given FSO. A similar trend of the response in the pattern of major PUFA was also observed in the plasma cholesterol ester fraction (data not shown). The fatty acid composition of epididymal adipose tissue in general reflected that of dietary fats, and $7.4 \mathrm{~g} / 100 \mathrm{~g}$ of $\alpha$-linolenic acid and $6.6 \mathrm{~g} / 100 \mathrm{~g}$ of pinolenic acid were found, but the proportion of linoleic acid was comparable among the three groups.

The magnitude of ADP-induced platelet aggregation, and aortic production of prostacyclin were not influenced by the type of dietary fat (data not shown). 


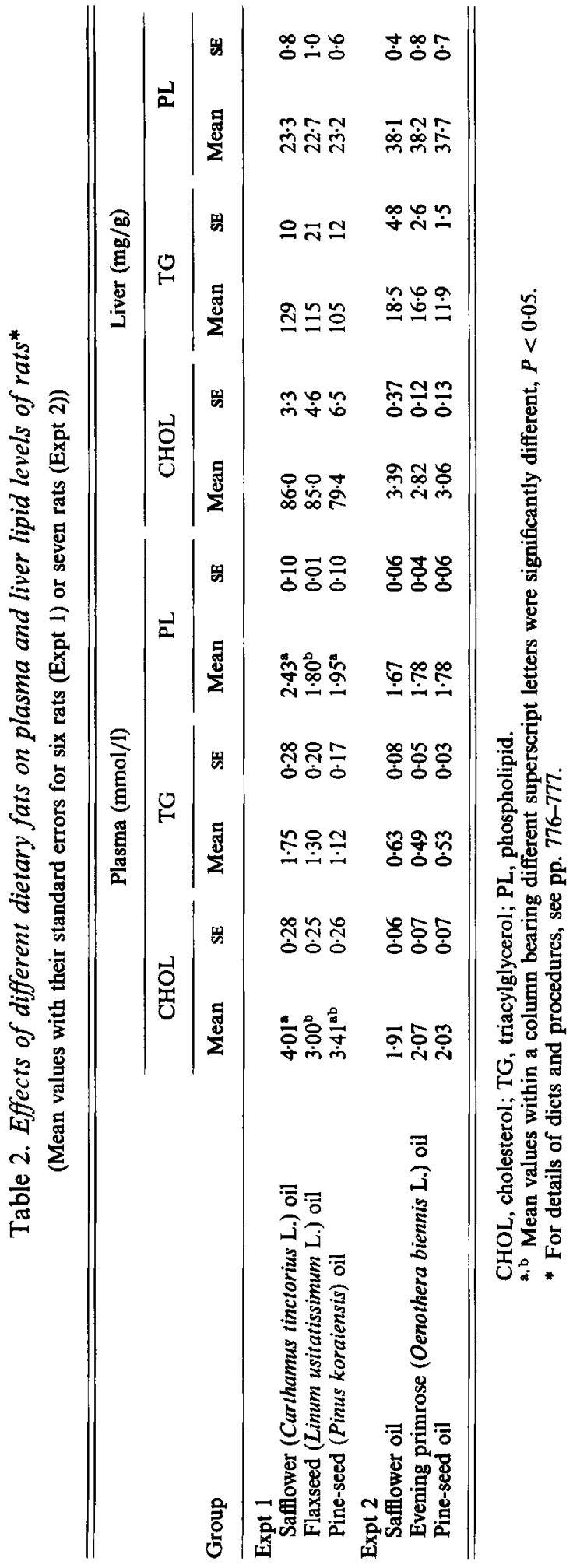


Table 3. Expt 1. Effects of different dietary fats on the polyunsaturated fatty acid composition $(\mathrm{g} / 100 \mathrm{~g}$ total fatty acids) of liver phosphatidylcholine in rats*

(Mean values with their standard errors for six rats)

\begin{tabular}{|c|c|c|c|c|c|c|}
\hline \multirow[b]{3}{*}{ Fatty acid } & \multicolumn{6}{|c|}{ Group } \\
\hline & \multicolumn{2}{|c|}{$\begin{array}{l}\text { Safflower (Carthamus } \\
\text { tinctorius L.) oil }\end{array}$} & \multicolumn{2}{|c|}{$\begin{array}{c}\text { Flaxseed (Linum } \\
\text { usitatissimum L.) oil }\end{array}$} & \multicolumn{2}{|c|}{$\begin{array}{c}\text { Pine-seed (Pinus } \\
\text { koraiensis) oil }\end{array}$} \\
\hline & Mean & $\mathrm{SE}$ & Mean & SE & Mean & $\mathrm{SE}$ \\
\hline $18: 2 n-6$ & $22 \cdot 6^{a}$ & 0.8 & $26.9^{b}$ & 0.7 & $16 \cdot 0^{c}$ & $1 \cdot 1$ \\
\hline $18: 3 \mathrm{PO}+$ & - & - & - & - & 4.8 & 0.3 \\
\hline $18: 3 n-3$ & - & - & 0.6 & 0.1 & - & - \\
\hline $20: 3 n-6$ & $2 \cdot 5$ & 0.2 & $2 \cdot 5$ & 0.2 & 2.5 & 0.2 \\
\hline $20: 4 n-6$ & $25 \cdot 6^{\mathrm{a}}$ & $1 \cdot 1$ & $17 \cdot 2^{b}$ & $1 \cdot 1$ & $26 \cdot 4^{b}$ & 0.7 \\
\hline $20: 5 n-3$ & - & - & $1 \cdot 1$ & 0.1 & - & - \\
\hline $22: 5 n-6$ & $0 \cdot 6^{\mathrm{a}}$ & 0.1 & - & - & $1 \cdot 2^{b}$ & 0.2 \\
\hline $22: 5 n-3$ & - & - & $1 \cdot 2$ & $0 \cdot 1$ & - & - \\
\hline $22: 6 n-3$ & $2 \cdot 0^{2}$ & 0.1 & $3 \cdot 2^{\mathrm{b}}$ & $0 \cdot 3$ & $1 \cdot 7^{\mathrm{a}}$ & 0.1 \\
\hline Desaturation index & $1 \cdot 25^{\mathrm{a}}$ & 0.06 & $0.74^{b}$ & 0.06 & $1 \cdot 86^{\circ}$ & $0 \cdot 16$ \\
\hline
\end{tabular}

a, b, c Mean values not sharing a common superscript letter were significantly different, $P<0.05$.

* For details of diets and procedures, see pp. 776-777.

+ Pinolenic acid (cis-5,cis-9, cis-12-octadecatrienoic acid).

$\ddagger$ Desaturation index: $(20: 3 n-6+20: 4 n-6) / 18: 2 n-6$.

Table 4. Expt 2. Effects of different dietary fats on the polyunsaturated fatty acid composition $(\mathrm{g} / 100 \mathrm{~g}$ total fatty acids) of liver phosphatidylcholine in rats*

(Mean values with their standard errors for seven rats)

\begin{tabular}{|c|c|c|c|c|c|c|}
\hline \multirow[b]{3}{*}{ Fatty acid } & \multicolumn{6}{|c|}{ Group } \\
\hline & \multicolumn{2}{|c|}{$\begin{array}{l}\text { Safflower (Carthamus } \\
\text { tinctorius L.) oil }\end{array}$} & \multicolumn{2}{|c|}{$\begin{array}{c}\text { Evening primrose } \\
\text { (Oenothera biennis L.) oil }\end{array}$} & \multicolumn{2}{|c|}{$\begin{array}{l}\text { Pine-seed (Pinus } \\
\text { koraiensis) oil }\end{array}$} \\
\hline & Mean & SE & Mean & $\mathrm{SE}$ & Mean & $\mathrm{SE}$ \\
\hline $18: 2 n-6$ & $16 \cdot 0^{\mathrm{a}}$ & $0 \cdot 3$ & $14 \cdot 0^{\mathrm{b}}$ & 0.4 & $11 \cdot 8^{c}$ & $0-2$ \\
\hline $18: 3 \mathrm{PO} \dagger$ & - & - & - & - & $2 \cdot 2$ & $0 \cdot 1$ \\
\hline $18: 3 n-6$ & $0 \cdot 5^{\mathrm{a}}$ & 0.0 & $0.8^{b}$ & 0.0 & - & - \\
\hline $20: 3 n-6$ & $0 \cdot 3^{a}$ & 0.0 & $0.4^{\mathrm{b}}$ & 0.0 & $0.7^{\mathrm{c}}$ & 0.0 \\
\hline $20: 4 n-6$ & $32 \cdot 3^{a}$ & 0.4 & $33 \cdot 4^{b}$ & 0.4 & $32 \cdot 0^{\mathrm{s}}$ & 0.2 \\
\hline $22: 5 n-6$ & $2 \cdot 8$ & 0.2 & $2 \cdot 9$ & 0.2 & 3.0 & $0 \cdot 1$ \\
\hline $22: 5 n-3$ & 0.2 & $0 \cdot 1$ & $0 \cdot 2$ & 0.1 & 0.2 & $0 \cdot 1$ \\
\hline $22: 6 n-3$ & $1 \cdot 7^{\mathrm{a}}$ & 0.1 & $2 \cdot 0^{\mathrm{b}}$ & 0.3 & $1 \cdot 8^{\mathrm{a}}$ & 0.0 \\
\hline Desaturation index $\neq$ & $2 \cdot 05^{a}$ & 0.06 & $2 \cdot 44^{b}$ & 0.09 & $2 \cdot 79^{\mathrm{c}}$ & 0.06 \\
\hline
\end{tabular}

a,b,c Mean values not sharing a common superscript letter were significantly different, $\boldsymbol{P}<0.05$.

* For details of diets and procedures, see pp. 776-777.

$\dagger$ Pinolenic acid (cis-5,cis-9,cis-12-octadecatrienoic acid).

†esaturation index: $(20: 3 n-6+20: 4 n-6) / 18: 2 n-6$. 

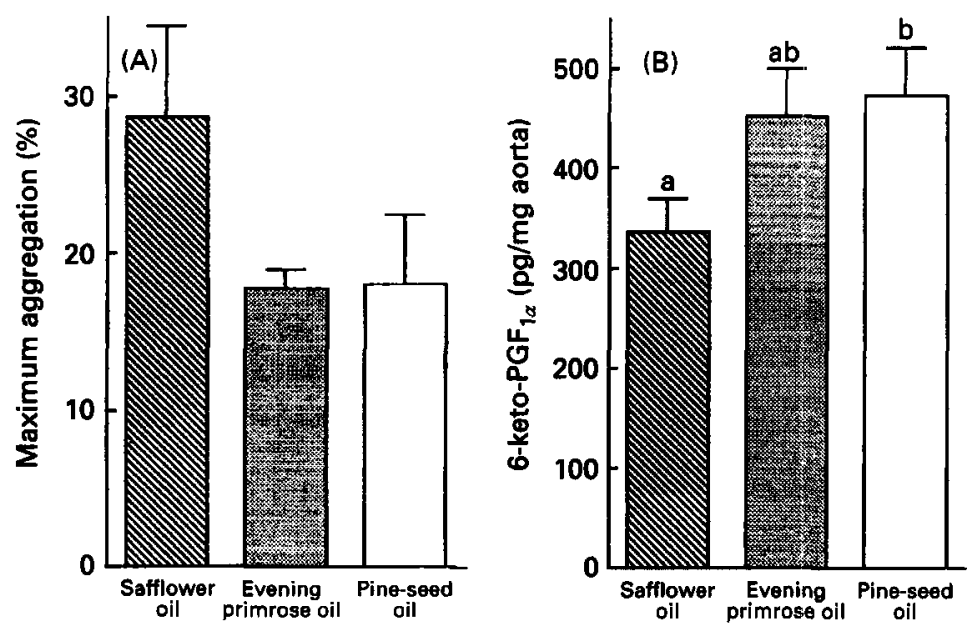

Fig. 1. Expt 2. Effects of different dietary fats on (A) platelet aggregation induced by ADP and (B) prostacyclin production by the thoracic aorta measured as 6-keto-prostaglandin $\mathrm{F}_{12}$ in spontaneously hypertensive rats. Values are means for seven rats, with their standard errors indicated by vertical bars. Columns bearing different superscript letters were significantly different $(P<0.05)$.

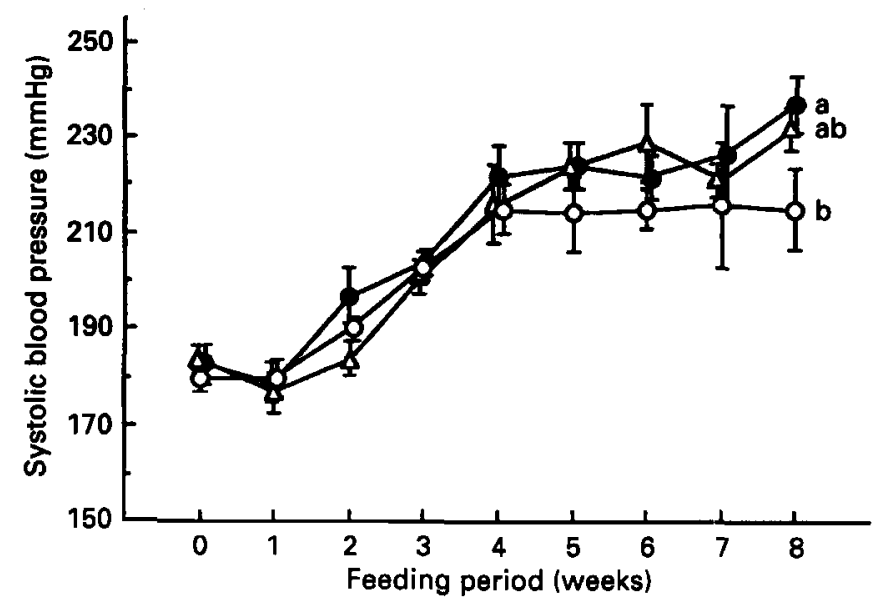

Fig. 2. Expt 2. Effects of different dietary fats on the systolic blood pressure of spontaneously hypertensive rats. $(\triangle)$, safflower (Carthamus tinciorius L.) oil; $(O)$, evening primrose (Oenothera biennis L.) oil; $(O)$, pine-seed (Pinus koraiensis) oil. Values are means for seven rats, with their standard errors indicated by vertical bars. Values not sharing a common letter were significantly different $(P<0.05)$.

\section{Expt 2. Effects of pine-seed oil in spontaneously hypertensive rats fed on diets free of cholesterol}

There were no differences in the growth variables among the groups. All groups of rats, initially weighing $245 \mathrm{~g}$, consumed 16.5 to $16.9 \mathrm{~g}$ diet/d and gained 363 to $368 \mathrm{~g}$ body weight over 8 weeks on average. Mean relative liver weight was 30.8 to $32.3 \mathrm{~g} / \mathrm{kg}$ body weight.

As shown in Table 2, dietary fat did not influence the concentration of various lipids in plasma and liver.

The PUFA composition of liver phosphatidylcholine is shown in Table 4. The content of linoleic acid in the dietary fat influenced its proportion in the phospholipid. The 
proportion of arachidonic acid was again comparable between the SAO and PSO groups, and it was slightly but significantly higher in the EPO group. However, the linoleic acid desaturation index was significantly higher in rats given PSO than in those given SAO as a result of a lower proportion of linoleic acid in the former.

The degree of platelet aggregation induced by ADP tended to be lower in the rats given EPO and PSO than in those given SAO, but the difference was not significant due to a large variation (Fig. 1A). EPO and PSO stimulated the aortic production of prostacyclin more than SAO, and the difference between the PSO and SAO groups was significant (Fig. 1B).

Fig. 2 shows the changes in systolic blood pressure over time. In rats given PSO the agerelated elevation of blood pressure was attenuated after 5 weeks of feeding and it remained apparently constant until 8 weeks, in contrast to a gradual increase in rats given either EPO or SAO. The difference between PSO and EPO at 8 weeks was significant.

\section{DISCUSSION}

A number of mechanisms have been proposed for the hypocholesterolaemic effects of PUFA, in particular linoleic acid, in comparison with saturated fatty acids (Ibrahim \& McNamara, 1988). These include interference with cholesterol and/or bile acid absorption and, hence, enhanced faecal steroid excretion; the reduction of hepatic cholesterol synthesis; the enhancement of cholesterol oxidation to bile acids; and the redistribution of cholesterol from the plasma compartment to the peripheral tissues. It is uncertain which mechanism(s) is responsible for the hypocholesterolaemic effect of PSO in comparison with SAO, i.e. pinolenic acid $v$. linoleic acid. Since PSO did not influence the concentration of liver cholesterol in rats fed on diets free of or enriched with cholesterol, it seems likely that a mechanism other than an intraluminal event operates. The inhibition of intestinal cholesterol absorption is usually accompanied by the reduction of hepatic cholesterol (Sugano et al. 1977). No hypocholesterolaemic effect of PSO in relation to SAO was observed in rats fed on cholesterol-free diets, but it is reasonable to consider that there will be no further reduction of plasma cholesterol when its level is low as observed here.

It is known that dietary cholesterol depresses the conversion of linoleic acid to arachidonic acid by inhibiting the activity of the rate-limiting enzyme, $\Delta 6$-desaturase (EC 1.14.99.25) (Brenner, 1989). The effect of PSO on the PUFA profile was apparent even in rats fed on diets high in cholesterol (Expt 2), but the magnitude of platelet aggregation and aortic production of prostacyclin were comparable among the different fats in this dietary regimen. This suggests that the effect of cholesterol overrides that of PUFA (Lee et al. 1991). Thus, when rats were given diets free of cholesterol there was a dietary fat-dependent difference in these variables, in particular prostacyclin production.

PSO, in contrast to FSO, neither interfered with the desaturation of linoleic acid, nor reduced aortic prostacyclin production. Prostaglandin synthesis is regulated by the supply of the substrate fatty acids, arachidonic acid in this case (Lands, 1991). These observations, together with the reducing tendency of platelet aggregation in relation to SAO, indicate the characteristic function of pinolenic acid in the regulation of PUFA metabolism.

It is unknown whether pinolenic acid itself or its metabolite(s) serve as the substrate for the production of physiologically active eicosanoids. Since the GLC analysis did not show a measurable degree of desaturation and elongation of pinolenic acid (Tables 3 and 4), the enzymes involved in these metabolic steps seem to discriminate the position of double bonds in the pinolenic acid molecule from that of $n-3$ and $n-6$ PUFA (Brenner, 1989) as in the case of columbinic acid (Houtsmuller, 1981). However, the results of the present study support the view that this peculiar trienoic acid may at least have favourable functions in the regulation of various lipid variables. If pinolenic acid does not stimulate production 
of prostaglandins such as $\mathrm{PGE}_{2}$ which may have diverse untoward effects on various lipidrelated disorders when excessively produced (Subbiah, 1978), its hypocholesterolaemic effect is valuable. This point deserves further study.

Several investigators have reported that $\gamma$-linolenic acid is less hypertensive than linoleic acid by comparing EPO and SAO (Hoffman \& Foster, 1983). This was not the case in the present study. In contrast, pinolenic acid prevented the rise of blood pressure after 5 weeks (Fig. 2). The mechanism by which pinolenic acid exerts such an effect is not apparent, but it is probable that this effect is mediated through the imbalance of prostaglandins, one of the factors influencing the blood pressure (Knapp, 1989), since this PUFA appears to influence differently the production of various prostaglandins, as can be presumed from its diverse effects on platelet aggregation and prostacyclin production.

The pine-seed oil used here contained less than $20 \mathrm{~g}$ non-saponifiable lipid fraction $/ \mathrm{kg}$. Although we did not analyse the nature of this fraction, it seems likely that plant sterols are the major ingredients. It is not expected that plant sterols in such a small amount occurring in the diet would exert a pharmacological effect.

In conclusion, although the present study provided only limited information on pinolenic acid occurring exclusively in Korean pine-seed oil, this peculiar trienoic acid, in comparison with linoleic acid, exerted diverse physiological functions which are in favour of the prevention and/or amelioration of various degenerative disorders such as hypercholesterolaemia, thrombosis and hypertension.

We thank Fuji Oil Company, Osaka for preparation of edible grade pine-seed oil. This study was supported by a Grant-in-Aid for Scientific Research B from the Ministry of Education, Culture and Science of Japan.

\section{REFERENCES}

American Institute of Nutrition (1977). Report of the American Institute of Nutrition ad hoc committee on standards for nutritional studies. Journal of Nutrition 107, 1340-1348.

Berger, A. \& German, J. B. (1991). Extensive incorporation of dietary $\Delta-5,11,14$ eicosatrienoate into the phosphatidylinositol pool. Biochimica et Biophysica Acta 1085, 371-376.

Brenner, R. R. (1989). Factors influencing fatty acid chain elongation and desaturation. In The Role of Fats in Human Nutrition, 2nd ed., pp. 45-79 [A. J. Vergroesen and M. Crawford, editors]. London: Academic Press.

Brox, J. H., Killie, J. E., Gunnes, S. \& Nordøy, A. (1981). The effect of cod liver oil and corn oil on platelets and vessel wall in man. Thrombosis and Haemostasis 46, 604-611.

Duncan, D. B. (1955). Multiple range and multiple F tests. Biometrics 11, 1-42.

Folch, J., Lees, M. \& Sloane-Stanley, G. H. (1957). A simple method for the isolation and purification of total lipids from animal tissues. Journal of Biological Chemistry 226, 497-506.

Hoffman, P. \& Foster, W. (1983). Effect of sunflowerseed oil, linseed oil, evening primrose oil and hydrogenated palm kernel oil on hypertension development in spontaneously hypertensive rats. Prostaglandins Leukotrienes and Medicine 11, 43-44.

Houtsmuller, U. M. T. (1981). Columbinic acid, a new type of essential fatty acid. Progress in Lipid Research 20, 889-896.

Ibrahim, J. B. T. \& McNamara, D. J. (1988). Cholesterol homeostasis in guinea pigs fed saturated and polyunsaturated fat diets. Biochimica et Biophysica Acta 963, 109-118.

Ikeda, I., Oka, T., Koba, K., Sugano, M. \& Lie Ken Jie, M. S. F. (1992). 5c-, 11c-, 14c-eicosatrienoic acid and 5c-, 11c-, 14c-, 17c-eicosatetraenoic acid of Biota orientalis seed oil affect lipid metabolism in the rat. Lipids 27, $500-504$.

Ikeda, I., Tomari, Y. \& Sugano, M. (1989). Interrelated effects of dietary fiber and fat on lymphatic cholesterol and triglyceride absorption in rats. Journal of Nutrition 119, 1383-1387.

Kinsella, J. E., Broughton, K. S. \& Whelan, J. W. (1990). Dietary unsaturated fatty acids: interactions and possible needs in relation to eicosanoid synthesis. Journal of Nutritional Biochemistry 1, 123-141.

Knapp, H. R. (1989). Omega-3 fatty acids, endogenous prostaglandins, and blood pressure regulation in humans. Nutrition Reviews 47, 301-313.

Koba, K., Abe, K., Ikeda, I. \& Sugano, M. (1992). Effects of $\alpha$-tocopherol and tocotrienols on blood pressure and linoleic acid metabolism in the spontaneously hypertensive rat (SHR). Bioscience Biotechnology and Biochemistry 56, 1420-1423. 
Lands, W. E. M. (1991). Biosynthesis of prostaglandins. Annual Review of Nutrition 11, 41-60.

Lee, J. H., Fukumoto, M., Nishida, H., Ikeda, I. \& Sugano, M. (1989). The interrelated effects of $n-6 / n-3$ and polyunsaturated/saturated ratios of dietary fats on the regulation of lipid metabolism in rats. Journal of Nutrition 119, 1893-1899.

Lee, J. H., Ikeda, I. \& Sugano, M. (1991). Dietary cholesterol influences on various lipid indices and eicosanoid production in rats fed dietary fat desirable for the protection of ischemic heart disease. Journal of Nutritional Science and Vitaminology 37, 389-399.

Subbiah, M. T. R. (1978). Prostaglandin $\mathrm{E}_{2}$ biosynthesis and effect in pigeon aorta. Atherosclerosis 29, 487-495.

Sugano, M., Kamo, F., Ikeda, I. \& Morioka, H. (1976). Lipid-lowering activity of phytosterols in rats. Atherosclerosis 24, 301-309.

Sugano, M. \& Lee, J. H. (1989). Nutritional and physiological significance of lipids. Journal of Dispersion Science and Technology 10, 643-665.

Sugano, M., Morioka, H. \& Ikeda, I. (1977). A comparison of hypocholesterolemic activity of $\beta$-sitosterol and $\beta$-sitostanol in rats. Journal of Nutrition 107, 2011-2019. 